Article

\title{
Induction of Apoptosis by PQ1, a Gap Junction Enhancer that Upregulates Connexin 43 and Activates the MAPK Signaling Pathway in Mammary Carcinoma Cells
}

\author{
Stephanie N. Shishido and Thu A. Nguyen * \\ Department of Diagnostic Medicine/Pathobiology, Kansas State University, Manhattan, KS 66506, USA; \\ snshishido@gmail.com \\ * Correspondence: tnguyen@vet.k-state.edu; Tel.: +1-785-532-4431; Fax: +1-785-532-4039 \\ Academic Editors: Anthony Lemarié and William Chi-shing Cho \\ Received: 26 June 2015; Accepted: 22 January 2016; Published: 29 January 2016
}

\begin{abstract}
The mechanism of gap junction enhancer (PQ1) induced cytotoxicity is thought to be attributed to the change in connexin 43 (Cx43) expression; therefore, the effects of $\mathrm{C} \times 43$ modulation in cell survival were investigated in mammary carcinoma cells (FMC2u) derived from a malignant neoplasm of a female FVB/N-Tg(MMTV-PyVT)634Mul/J (PyVT) transgenic mouse. PQ1 was determined to have an $\mathrm{IC}_{50}$ of $6.5 \mu \mathrm{M}$ in FMC2u cells, while inducing an upregulation in Cx43 expression. The effects of $\mathrm{Cx} 43$ modulation in FMC2u cell survival was determined through transfection experiments with Cx43 cDNA, which induced an elevated level of protein expression similar to that seen with PQ1 exposure, or siRNA to silence Cx43 protein expression. Overexpression or silencing of $\mathrm{Cx} 43$ led to a reduction or an increase in cell viability, respectively. The mitogen-activated protein kinase (MAPK) family has been implicated in the regulation of cell survival and cell death; therefore, the gap junctional intercellular communication (GJIC)-independent function of PQ1 and Cx43 in the Raf/Mitogen-activated protein kinase/ERK kinase/extracellular-signal-regulated kinase (Raf-MEK-ERK) cascade of cellular survival and p38 MAPK-dependent pathway of apoptosis were explored. PQ1 treatment activated p44/42 MAPK, while the overexpression of $\mathrm{Cx} 43$ resulted in a reduced expression. This suggests that PQ1 affects the Raf-MEK-ERK cascade independent of $\mathrm{C} \times 43$ upregulation. Both overexpression of $\mathrm{C} \times 43$ and PQ1 treatment stimulated an increase in the phosphorylated form of p38-MAPK, reduced levels of the anti-apoptotic protein $\mathrm{Bcl}-2$, and increased the cleavage of pro-caspase-3. Silencing of $\mathrm{C} \times 43$ protein expression led to a reduction in the phosphorylation of p38-MAPK and an increase in Bcl-2 expression. The mechanism behind PQ1-induced cytotoxicity in FMC2u mammary carcinoma cells is thought to be attributed to the change in Cx43 expression. Furthermore, PQ1-induced apoptosis through the upregulation of Cx43 may depend on p38 MAPK, highlighting that the effect of PQ1 on gap junctions as well as cellular survival via a MAPK-dependent pathway.
\end{abstract}

Keywords: connexin 43; PQ1; gap junction; apoptosis; MAPK

\section{Introduction}

Breast cancer is the most common cancer in women worldwide, and mortality from breast cancer is consistent due to tumor invasion and metastasis [1]. Cell and animal models help to further the understanding of breast cancer pathogenesis and provide insight into treatment options. In vivo studies are crucial for drug development, but many drugs do not translate from in vitro to in vivo. The use of a cell line derived from an animal with clinical features of human breast cancer can be 
utilized to screen drugs prior to use in the animal itself. Although a number of breast cancer cell lines has been established, a limited number of cell lines is available derived from a transgenic mouse model of spontaneous mammary carcinomas. The establishment of such a line would provide another method to study tumor growth and therapeutic effects despite genetic predisposition for cancer formation. Previously, the transgenic strain FVB/N-Tg(MMTV-PyVT)634Mul/J (also known as PyVT) was used as a model system for measuring tumor burden, drug sensitivity, and metastasis of mammary carcinomas [2]. Here a new cell line, female mammary carcinoma cells (FMC2u), was established from the primary tumor tissue resected from a late stage PyVT mouse with an aggressive, metastatic phenotype. FMC2u was characterized by morphology, receptor expression levels, proliferative and migratory abilities, invasiveness, and colony formation. The anticancer effects on FMC $2 u$ cell growth were determined for gap junction enhancers (PQs).

Multiple molecular processes are affected by gap junctional intercellular communication (GJIC), including proliferation, differentiation, migration and apoptosis [3,4]. One of the hallmarks of cancer is the loss of GJIC and connexins, the gap junction proteins [5]. Connexins are therapeutic targets in cancer treatment through both a GJIC-dependent mechanism and a GJIC-independent mechanism [6]. Connexins exhibit a tumor suppressive function via a GJIC-independent manner by interacting and regulating molecules and genes involved in tumorigenesis [7]. The substituted quinolines (PQ1 and PQ7) are gap junction enhancers that have been shown to significantly increase GJIC while reducing breast cancer cell viability [8-10]. The inhibitory ability of PQs was tested on FMC2u cellular growth, showing that PQ1 significantly reduced proliferation and viability while increasing Connexin 43 (Cx43) expression. This observation suggests that $\mathrm{Cx} 43$ contributes to the anticancer effects of PQ1.

The role of $\mathrm{Cx} 43$ in PQ1 induced cytotoxicity was further determined via modulation of expression by transfection experiments in FMC2u cells. Specifically we evaluated the effects of $\mathrm{Cx} 43$ modulation on the Raf/Mitogen-activated protein kinase/ERK kinase/extracellular-signal-regulated kinase (Raf-MEK-ERK) cascade and the p38 mitogen-activated protein kinase (MAPK) apoptotic pathway. The MAPKs are signaling pathways critical for the conversion of various extracellular signals to biological responses [11]. In particular, extracellular-signal-regulated kinase (ERK) activation is generally related to cell survival, while reports indicate that apoptosis is associated with the activation of p38 MAPK [11-13]. This study explores the role of Cx43 in relation to PQ1 induced cytotoxicity.

\section{Results}

\subsection{Morphology and Growth Characteristics of Female Mammary Carcinoma Cells (FMC2u)}

Histologically, the parental tumor was classified as a late carcinoma composed of nests of neoplastic cells that frequently mitosed (Figure 1A). Cells within the tumor contained large pleomorphic nuclei and prominent nucleoli. Characteristic features of the cell line are similar to the parental tumor type and have remained constant despite the number of passages. Cultured FMC $2 u$ cells grew as adherent undifferentiated cells (Figure 1B). The nuclei varied in size and little cytoplasm were observed. Cells grew as interlacing colonies with disorganized growth patterns. At heavy cell density the cells were observed to pile upon each other.

Optimal growth conditions were determined via proliferation and viability tests. RPMI media (with or without insulin) with 10\% fetal bovine serum (FBS) was found to provide the best conditions for both proliferation and viability of FMC2u (Data not shown). RPMI was used for all following studies. The approximate doubling time was observed to be $24 \mathrm{~h}$ (Figure 1C). The growth rate decreased at high cell densities. Invasiveness was determined by the use of transwells with an 8 micron pore membrane. Cells were tested for movement from an insert with $0 \%$ FBS to a receiver with 10\% FBS RPMI media. Cells were able to transverse the membrane after 24 and $48 \mathrm{~h}$ of incubation (Data not shown). Using a "wound" assay FMC2u were observed to migrate efficiently across an adherent surface to form a monolayer of cells (Figure 1D). In $60 \mathrm{~h}$, a $1 \mathrm{~mm}$ section was completely closed. Colony 
formation was determined by use of a soft agar assay in which individual cells were seen proliferating in the agar matrix. Over a 15 day period, large colonies were formed (Figure 1E).
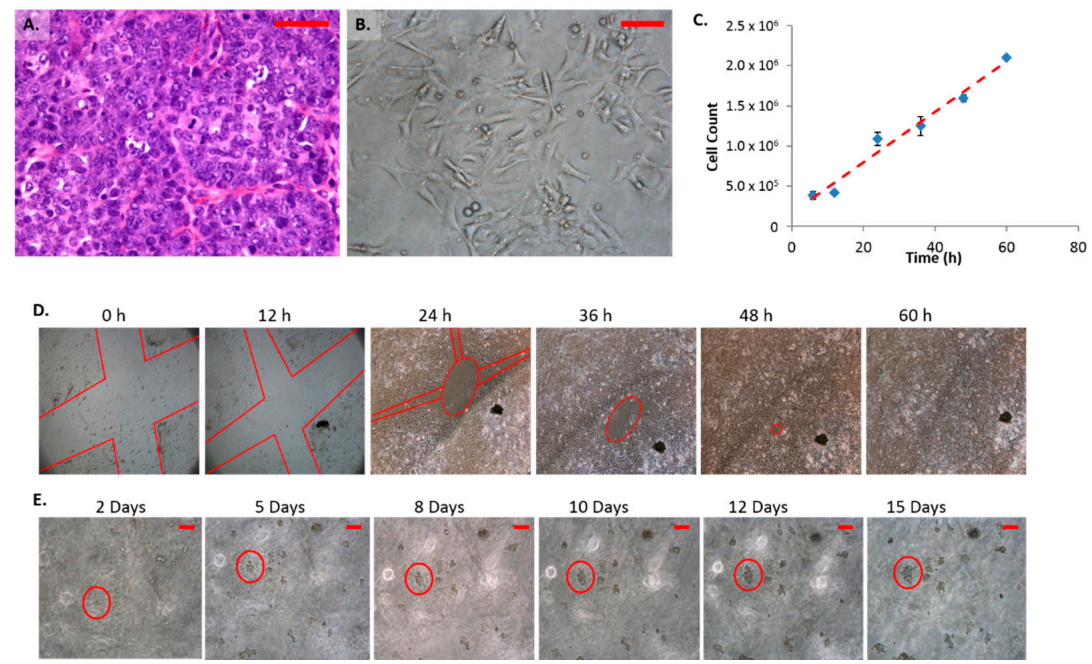

10 Days

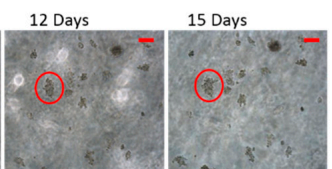

Figure 1. Characteristics of mammary carcinoma (FMC2u) cells. (A) H\&E of primary tumor isolated from late stage PyVT female at $40 \times$, Scale bar $=50 \mu \mathrm{m}$; (B) Micrograph of FMC2u in cell culture at 20 Nguyen, $\times$, Scale bar $=20 \mu \mathrm{m}$; (C) Proliferation of FMC2u cells with an approximate doubling time of 24 h; (D) Migration assay. Red lines indicate a cross section " $X$ " cut in the initial monolayer, approximately $1 \mathrm{~mm}$ in diameter. Cells were maintained in RPMI with $10 \%$ fetal bovine serum (FBS). Images taken every $12 \mathrm{~h}$ at $4 \times$. Wound was completely closed by $60 \mathrm{~h}$; (E) Colony formation in soft agar. 10,000 cells seeded on $0.8 \%$ agar RPMI and covered with $0.4 \%$ agar RPMI. Images were taken every $24 \mathrm{~h}$ at $10 \times$. Purple circle follows the growth of a few cells at $48 \mathrm{~h}$ to a solid colony at 15 days. Scale bar $=100 \mu \mathrm{m}$.

\subsection{Protein Phenotype of FMC2u Cells}

FMC2u cells were determined to be of epithelial origin using the molecular markers $E$-cadherin, occludin, and claudin-1 (Figure 2A). Additionally, the hormone receptor profile was quantified by Western blot analysis which revealed low expression of estrogen receptors $\alpha(E R \alpha)$ and $\beta(E R \beta)$, as well as the progesterone receptor (PR), with strong expression of human epidermal growth factor receptor 2 (HER2) (Figure 2B).

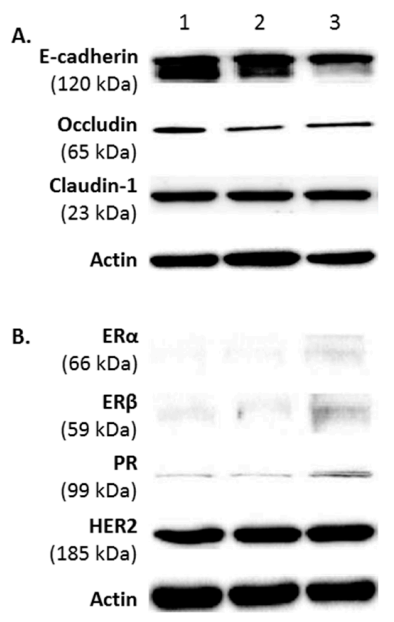

Figure 2. Cont. 


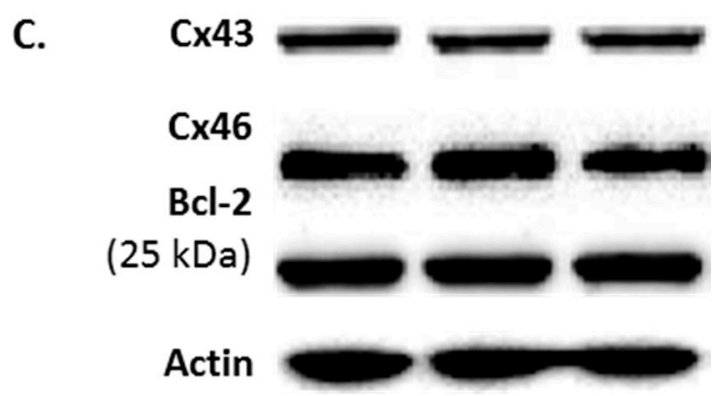

Figure 2. A phenotypic profile of FMC2u cells. Western blot analysis of three different samples of FMC2u (\#1-3). (A) Images of the epithelial markers E-cadherin, occludin, and claudin-1; (B) expression of estrogen receptor (ER $\alpha$ and $E R \beta)$, progesterone receptor (PR), and human epidermal growth factor receptor 2 (HER2); and (C) expression of gap junction proteins (connexin 43 and 46) and molecular marker Bcl-2 are shown using antibodies against specific protein. Actin used as a loading control.

Gap junction intercellular communication (GJIC) has an important function in maintaining tissue homeostasis. GJIC is the process in which small metabolites are shared directly by contiguous cells that have their cytoplasms connected by aqueous channels called gap junctions. FMC2u cells expressed both $\mathrm{Cx} 43$ and $\mathrm{Cx} 46$ (Figure 2C).

$\mathrm{Bcl}-2$ is an antiapoptotic protein that is a key regulator of apoptosis [14] and associated with low-grade, slowly proliferating, ER+ breast cancer $[15,16]$. Overexpression of Bcl-2 has been identified in a variety of malignancies and is one of the 21 genes used as a prognostic signature in Oncotype DX, a diagnostic test for the likely benefit from certain types of chemotherapy [17]. FMC2u cells were shown to have a high expression of Bcl-2 (Figure 2C).

\subsection{Effects of Treatment with Gap Junction Enhancers}

A class of substituted quinolines was described in Shi et al. $[9,18,19]$ and the effects of the first and second generation compounds (PQ1 and PQ7, respectively) as gap junction enhancers in breast cancer cell lines have been explored in previous studies.

\subsection{Cellular Proliferation and Viability}

The gap junction enhancers were tested for their inhibitory capacity on FMC2u cells. PQ1 was shown to have an $\mathrm{IC}_{50}$ of $6.5 \mu \mathrm{M}$ over a $24 \mathrm{~h}$ treatment period, while a $48 \mathrm{~h}$ treatment period required an increase to $8 \mu \mathrm{M}$ to reduce viability by $50 \%$ (Figure $3 \mathrm{~A}$ ). This suggests that the effect of PQ1 on FMC2u cells is time and dose dependent. The effects of treatment were also seen in the total cell count after each treatment period (Figure 3B), indicating that the proliferative ability of the cells is compromised. PQ7 was shown to be ineffective at all concentrations tested (Data not shown).

To determine if the observed reduction in growth and viability of FMC2u cells after PQ1 treatment was due to activation of the apoptotic pathway, the expression of cleaved caspase- 3 was examined. Apoptosis is a highly regulated cell suicide mechanism and the cleavage of protein substrates by caspases is unique to apoptotic cells. PQ1 treatment over a $24 \mathrm{~h}$ period led to a significant increase in cleaved caspase- 3 expression at all concentrations tested ( $p$-value ( $_{\mu M}=0.00556, p$-value $2.5 \mu M=0.00026$, $p$-value $5 \mu M=0.02237$; Figure 3C). This indicates that PQ1 activates apoptosis in FMC2u cells. 
A.
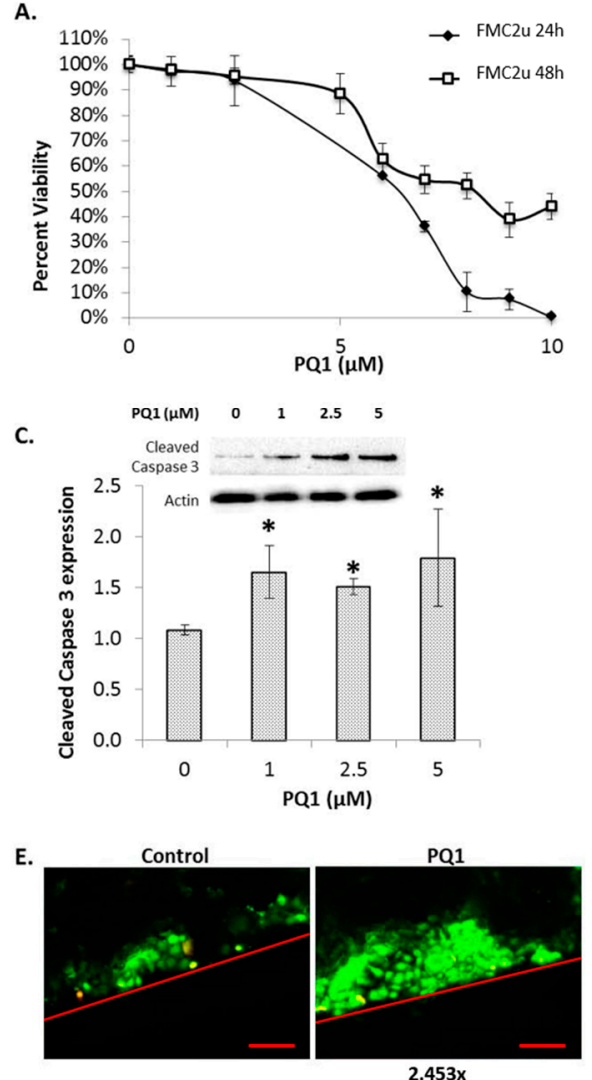
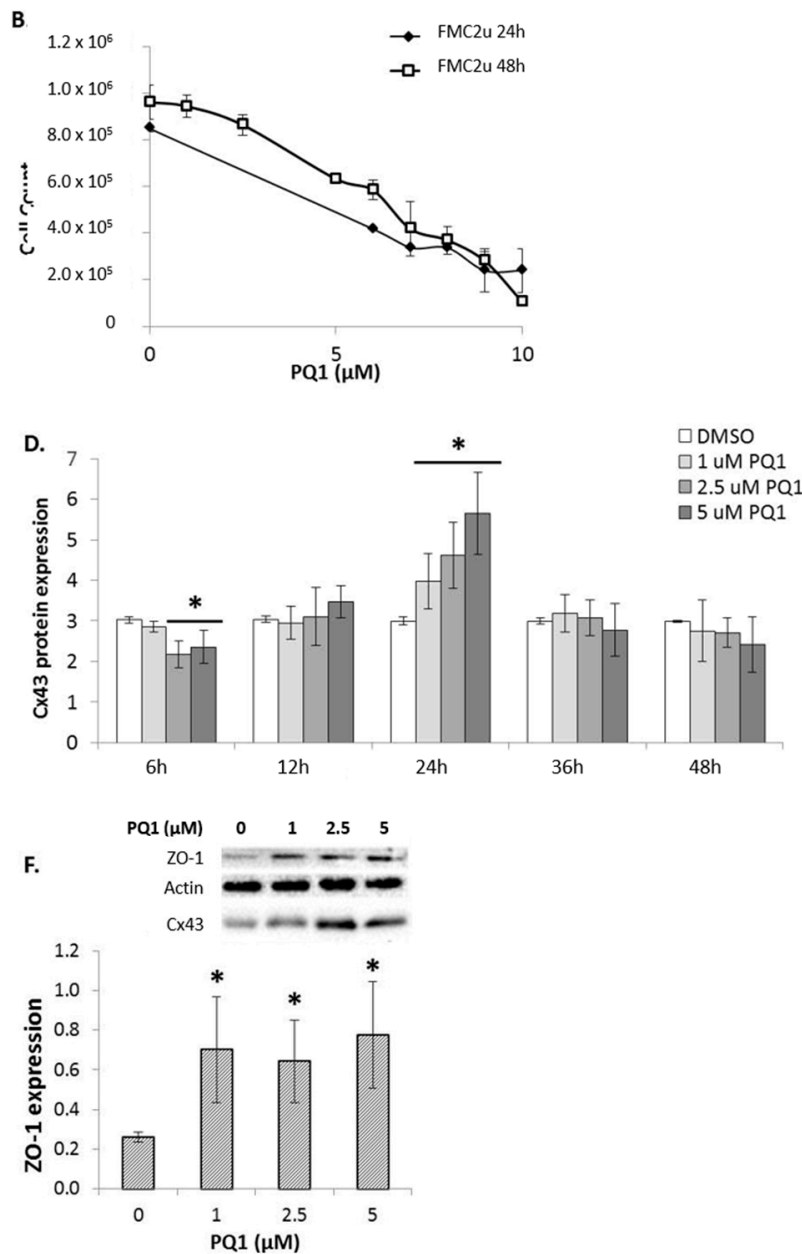

Figure 3. The effects of gap junction enhancer (PQ1) treatment on FMC2u. (A) Cellular viability and (B) proliferation determined by Acridine Orange/Propidium Iodide (AO/PI) after PQ1 treatment over either 24 or $48 \mathrm{~h}$ with varying concentrations; (C) Raw and graphical representation of the relative expression of cleaved caspase- 3 in FMC2u cells after treatment with $0,1,2.5$, and $5 \mu \mathrm{M}$ PQ1 over a $24 \mathrm{~h}$ period; (D) Graphical representation of Cx43 protein expression in FMC2u cells treated with PQ1 over 6, 12, 24, 36, and 48 h; (E) Gap junction activity of FMC2u determined by scrape load dye transfer after treatment with DMSO (control) or PQ1 at $1 \mu \mathrm{M}$, for $2 \mathrm{~h}$. Red lines indicate a cross section cut of initial dye. Lucifer yellow was used as a gap junctional dye and Rhodamine-dextran used to mark the cut site. Green fluorescence indicates the passage of dye form the cutting site, showing GJIC. Scale bar $=100 \mu \mathrm{m}$; (F) Raw and graphical representation of the relative ZO-1 in Cx43-immunoprecipitated complex of FMC2u cells after treatment with $0,1,2.5$, and $5 \mu \mathrm{M}$ PQ1 over a $24 \mathrm{~h}$ period. Actin used as a loading control. All experiments conducted with a sample size of three. * $p$-value $<0.05$ compared to DMSO control.

\subsection{Connexin Expression}

Previous studies have shown that PQ1 may induce an upregulation of Cx43 in neoplastic cells [20,21]. When Cx43-deficient MCF-7 breast cancer cells were transfected with Cx43, the cell-cell communication was restored and their malignant properties including anchorage-independent growth, migration and invasion were reduced, suggesting the role ofCx43 as a tumor suppressor. Immunoblot analysis of Cx43 expression was conducted for FMC2u cells treated with 1, 2.5, and $5 \mu \mathrm{M}$ PQ1 for 6, 12, 24, 36, and $48 \mathrm{~h}$ periods (Figure 3D and Supplemental Figure S1). At $24 \mathrm{~h}$ post PQ1 exposure, Cx43 expression is shown to significantly increase in a linear fashion ( $p$-value $<0.05)$. Interestingly, $6 \mathrm{~h}$ post 
treatment, 2.5 and $5 \mu \mathrm{M}$ PQ1 induced a reduction in Cx43 expression. The anticancer effects of PQ treatment on FMC2u cells may be due to the induced alterations in Cx43 expression.

\subsection{Gap Junctional Intercellular Communication (GJIC)-Dependent Effect: GJIC and Connexin Protein Binding}

To determine functionality of the gap junctions scrape load dye transfer was performed on FMC2u cells with either control (DMSO) or $1 \mu \mathrm{M}$ PQ1 for $2 \mathrm{~h}$ (Figure 3E). The untreated FMC2u cells have functional GJIC, seen from the passage of dye from the cut site to cells further away. PQ1 treatment increased the distance of dye transfer 2.453-fold, indicating an increase in GJIC. The anticancer effects of PQ treatment on FMC2u cells may be due to alterations in Cx43 expression.

Cx43 plays a role in protein binding, specifically to zona occludens- 1 (ZO-1). The C-terminal domain of $\mathrm{Cx} 43$ contains several phosphorylation sites with signaling motifs which binds to the PDZ domain of ZO-1 [22]. Previous studies showed that endogenous Cx43 and ZO-1 colocalized at the gap junctions [22], suggesting that $\mathrm{ZO}-1$ recruits signaling proteins into the gap junction channel. Immunoprecipitation of $\mathrm{Cx} 43$ led to the quantification of bound ZO-1. PQ1 treatment of FMC2u cells resulted in an increase in ZO- 1 after $24 \mathrm{~h}$ of treatment independent of concentration ( $p$-value $<0.05$; Figure 3F). The observed increase in bound ZO- 1 to $\mathrm{Cx} 43$ indicates an increase in signaling molecules recruited to the gap junction. This data indicates that PQ1 has a GJIC-dependent mechanism of action.

\subsection{GJIC-Independent Effect: MAPK Signaling}

To determine if PQ1 had affected GJIC-independent apoptotic signaling, alterations in the expression of multiple players in the MAPK pathway were identified. Treatment of $5 \mu \mathrm{M}$ PQ1 induced a significant increase in cRaf expression (Figure 4A). This suggests that PQ1 treatment modulates cRaf expression. Raf kinases are best known as key regulators of the MEK/ERK cascade, and up-regulated signaling through the RAF/MEK/ERK pathway has an important role in cancer [23,24]. Changes in the phosphorylation levels of key proteins in the RAF/MEK/ERK pathway were determined by Western blot analysis. PQ1 treatment over a $24 \mathrm{~h}$ period induced an increase in phospho-p44/42-MAPK at 2.5 and $5 \mu \mathrm{M}$ PQ1 ( $p$-value $=0.02606$ and 0.00946 , respectively; Figure 4B). There were no changes in p44/42-MAPK expression due to PQ1 treatment or transfection experiments. This data indicates PQ1 indirectly alters the ERK1/2 signaling cascade.

A.
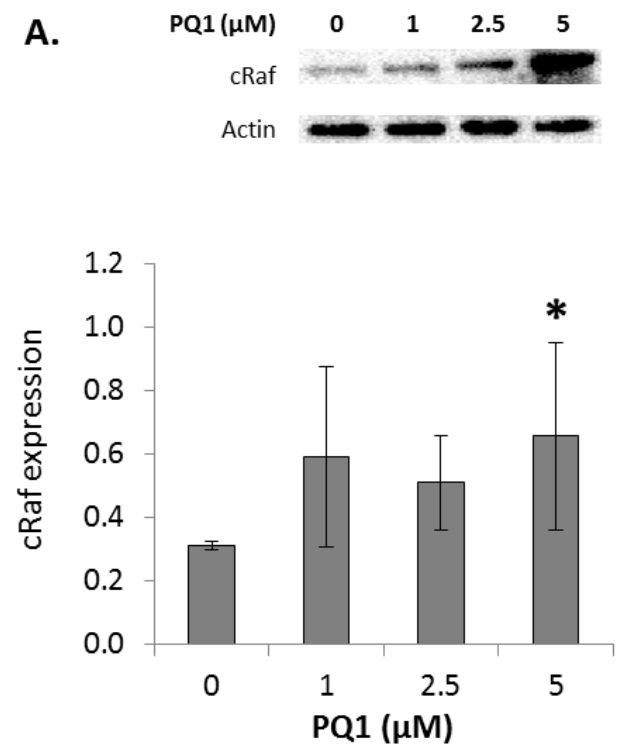
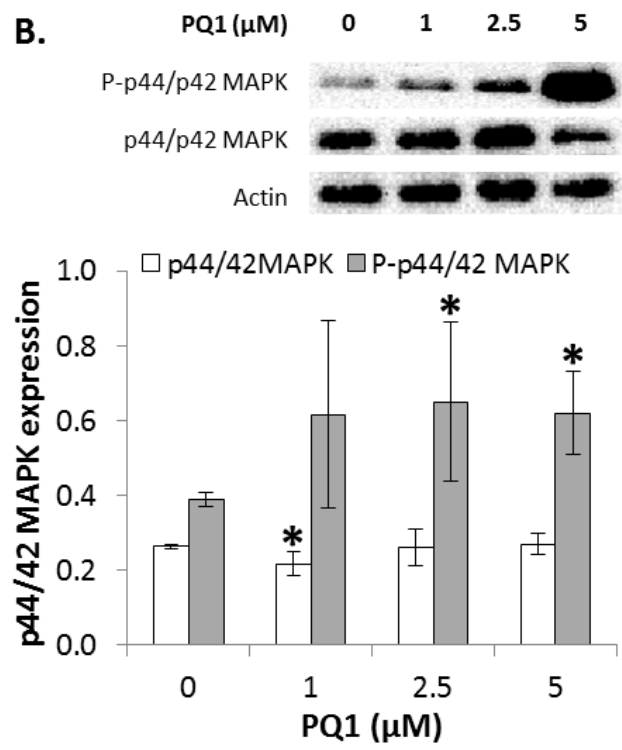

Figure 4. Cont. 

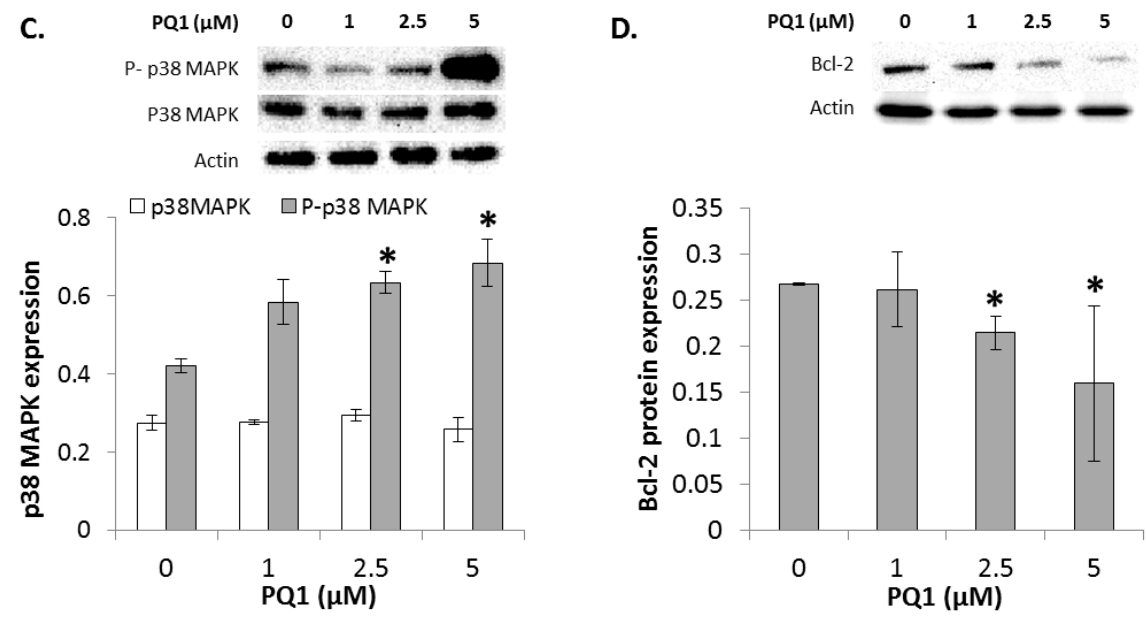

Figure 4. Expression of signaling molecules after treatment with PQ1. Raw and graphical representation of (A) cRaf; (B) p44/42 MAPK (P: phosphorylated); (C) p38 MAPK (P: phosphorylated), and (D) Bcl-2 in FMC2u cells after treatment with $0,1,2.5$, and $5 \mu \mathrm{M}$ PQ1 over a $24 \mathrm{~h}$ period. Actin used as a loading control. All experiments conducted with a sample size of three. ${ }^{*} p$-value $<0.05$ compared to DMSO control.

Another MAPK family member is the stress-activated protein kinase (p38-MAPK). PQ1 treatment over a $24 \mathrm{~h}$ period induced an increase in phosphorylated p38-MAPK when exposed to 2.5 and $5 \mu \mathrm{M}$ PQ1 ( $p$-value $=0.01545$ and 0.03686, respectively; Figure $4 \mathrm{C}$ ). There were no changes in p38-MAPK expression after PQ1 treatment. PQ1, therefore, indirectly alters p38-MAPK signaling cascade, suggesting a MAPK-dependent pathway of apoptosis.

Expression of the antiapoptotic protein Bcl-2 was next determined. This molecular marker is part of a group of antiapoptotic proteins that have been shown to be an important factor in the development of apoptotic resistance. Previous studies have demonstrated that MAPK pathway is active in Bcl-2 overexpressing cancer cells under stressful conditions [25]. Bcl-2 phosphorylation by activated p38-MAPK is a key event in the early induction of apoptosis under conditions of cellular stress [26]. PQ1 has been reported to induce apoptosis in human breast cancer cells through the upregulation of caspases and an alteration in Bax/Bcl-2 expression ratio [21,27]. Exposure to 2 and $5 \mu \mathrm{M}$ PQ1 induced a significant reduction in Bcl-2 expression in FMC2u cells ( $p$-value $=0.00968$; Figure 4D). PQ1 treatment affects apoptotic signaling through Bcl-2 expression, possibly due to increased phosphorylation of p38-MAPK.

\subsection{The Effects of Modulating Connexin 43 Protein Expression}

To determine if the anti-proliferative and apoptotic effects of PQ1 treatment were due to the observed change in Cx43 expression, FMC2u cells were transfected with Cx43 cDNA to induce overexpression. Overexpression of $\mathrm{Cx} 43$ was successfully accomplished with an approximate threefold increase in protein expression at $6 \mathrm{~h}$ post transfection (Figure 5A). The effects of reduced $\mathrm{Cx} 43$ expression were also examined by the transfection of $\mathrm{Cx} 43$ siRNA, which successfully silenced approximately $65 \%$ of expression at $24 \mathrm{~h}$ post transfection (Figure $5 \mathrm{~B}$ ).

\subsection{Cellular Proliferation and Viability}

Overexpression of Cx43 in FMC2u cells had an $86 \%$ viability at $6 \mathrm{~h}$ post transfection $(p$-value $=0.0037)$ and remained significantly lower than control cells (Figure 5C). However, silencing of $\mathrm{Cx} 43$ by siRNA had a $5 \%$ increase in cell viability at $48 \mathrm{~h}$ post transfection ( $p$-value $=0.0203$, Figure 5C). The total cell count was increased at $36 \mathrm{~h}$ post-transfection of Cx43 $(p$-value $=0.0150 ;$ Figure 5D). Silencing of $\mathrm{Cx} 43$ reduced total number of cells at 24 and $36 \mathrm{~h}$ 
$(p$-value $24 \mathrm{~h}=0.0107$ and $p$-value $36 \mathrm{~h}=0.0203$; Figure 5D). Modulation of Cx43 expression significantly affects the growth and viability of FMC2u cells.

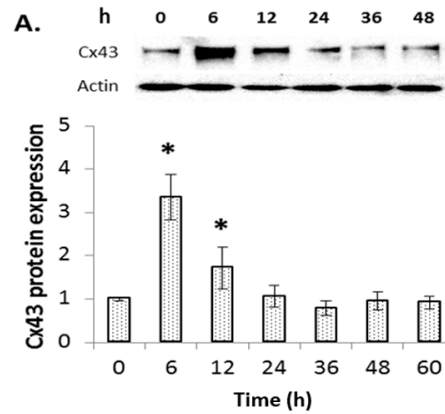

c.

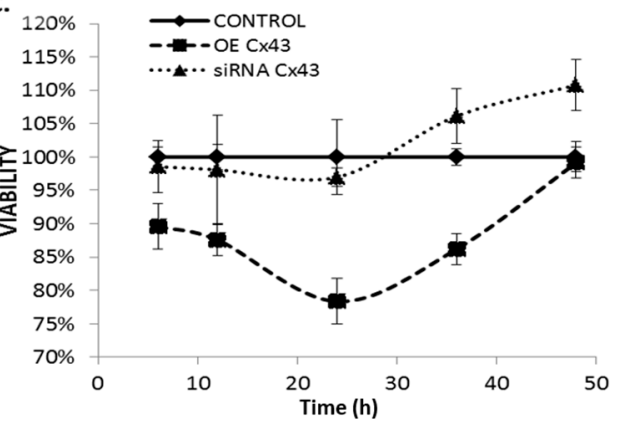

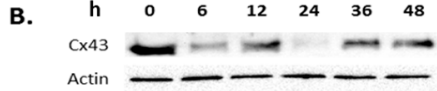

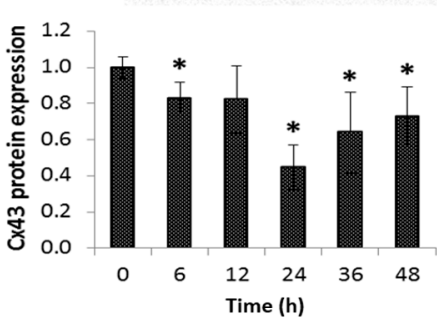

D.

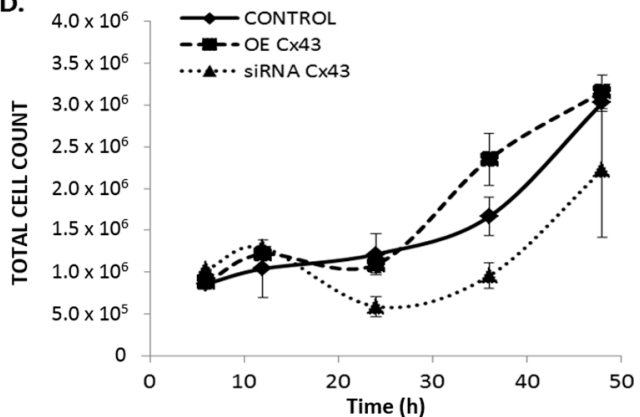

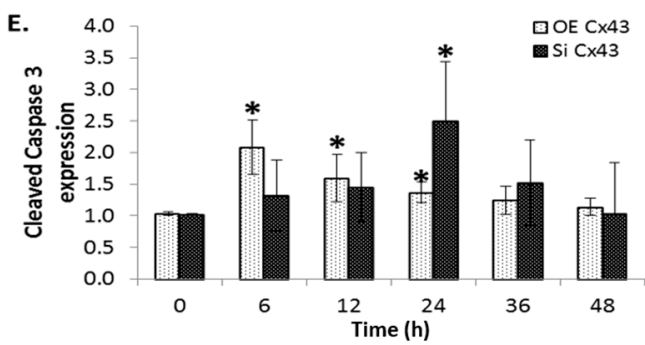

Figure 5. Modulation of connexin 43 expression affects proliferation and viability of FMC2u cells. (A) Graphical representation of fold protein induction from western blot analysis of Cx43 in FMC2u cells transfected with GFP-Cx43 cDNA vectors; (B) Graphical representation of fold protein induction from western blot analysis of Cx43 in FMC2u cells transfected with siRNA of Cx43; (C) Viability and (D) Total cell count either overexpressing (OE) Cx43 or with silenced (siRNA) Cx43 compared to normal unmodified cells; (E) Graphical representation of cleaved caspase-3 expression in FMC2u cells post transfection. All experiments conducted with a sample size of $n=3 .{ }^{*} p$-value $<0.05$ compared to respective transfection control.

The expression of cleaved caspase-3, a ubiquitously distributed caspase and the main effector caspase of apoptosis, was determined post transfection of FMC $2 u$ cells. Overexpression of Cx43 via transfection of cDNA significantly increased expression of cleaved caspase- 3 at 6,12 , and $24 \mathrm{~h}$ post

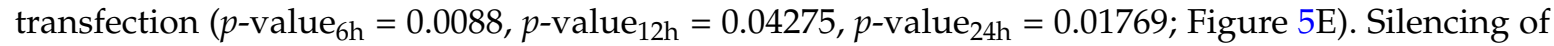
Cx43 significantly increased cleaved caspase- 3 expression at $24 \mathrm{~h}$ post transfection ( $p$-value $=0.035$; Figure 5E). Both the overexpression and silencing of Cx43 led to activation of apoptosis in FMC2u cells. This suggests that $\mathrm{Cx} 43$ is highly regulated within the cell, and variation in expression levels can trigger cell suicide.

\subsection{GJIC-Dependent Effect: GJIC and Connexin Protein Binding}

To confirm that the overexpression of $\mathrm{C} x 43$ led to functional gap junctions, scrape load dye transfer was conducted. Figure 6A shows an increase in dye transfer in FMC2u cells overexpressing 
Cx43 compared to control cells. Additionally the silencing of Cx43 resulted in reduced dye transfer in FMC2u cells, indicating a loss of GJIC (Figure 6A). This suggests that exogenous Cx43 assists in the formation of functional gap junctions in FMC2u cells.

A.
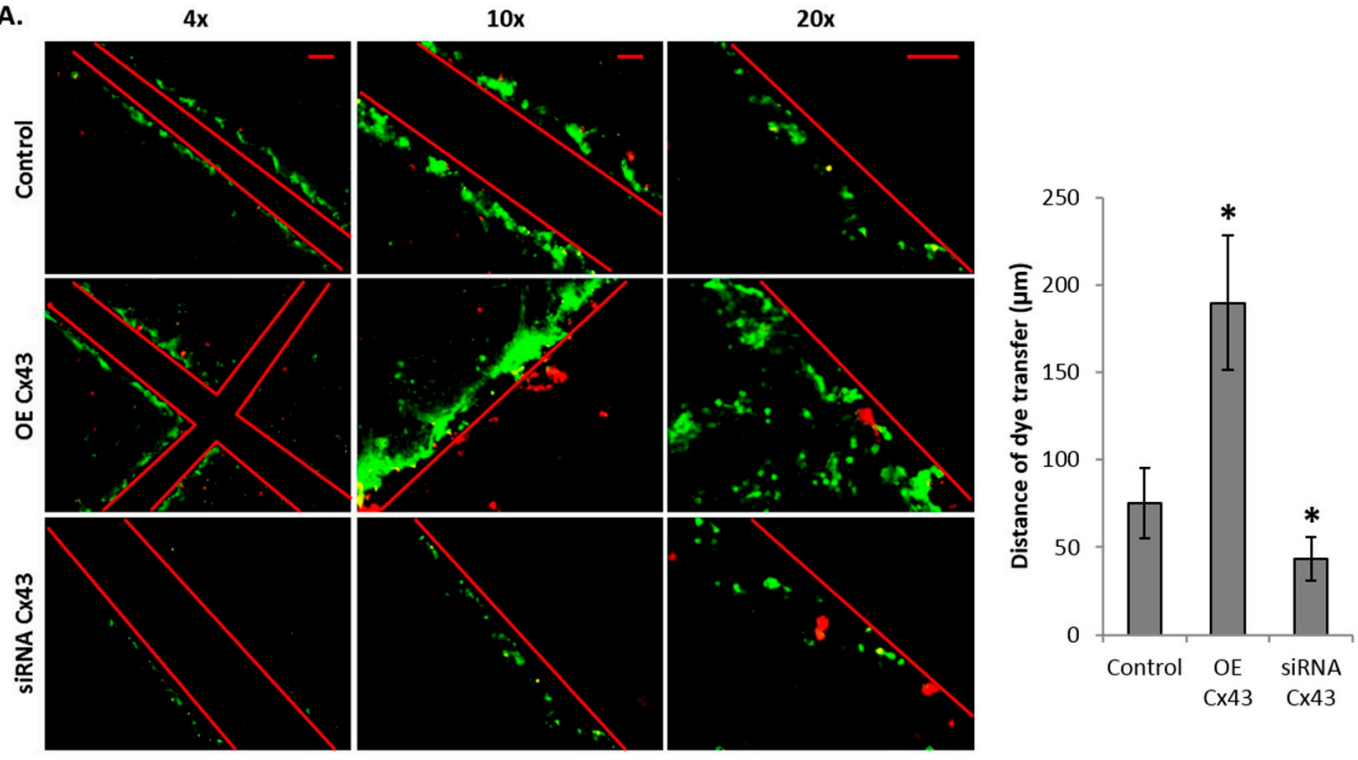

B.

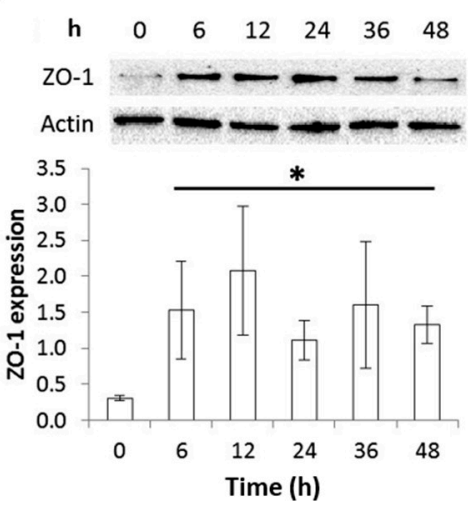

c.

SiRNA CX43

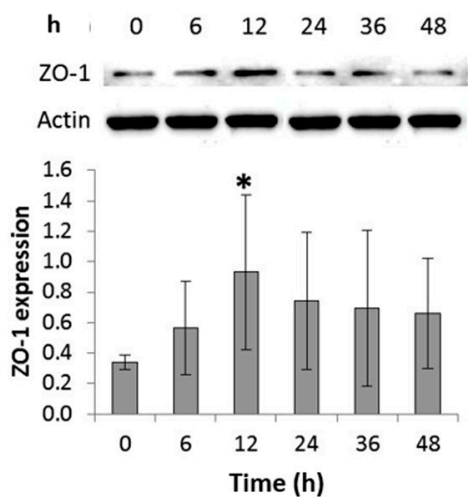

Figure 6. Modulation of connexin 43 expression affects GJIC. (A) Gap junction activity of FMC2u determined by scrape load dye transfer after transfection with empty vector (control), GFP-Cx43 cDNA vector, or siRNA Cx43. A graphical representation of dye transfer in $\mu \mathrm{m}$ was shown next to the images. Red lines indicate a cross sectional cut. Lucifer yellow was used as a gap junctional dye and Rhodamine-dextran used to mark the cut site. Green fluorescence indicates the passage of dye form the cutting site. Images taken at $4 \times, 10 \times$, and $20 \times$. Scale bar $=100,100,50 \mu \mathrm{m}$, respectively. Graphical representation of ZO-1 expression in Cx43-immunoprecipitated FMC2u cells at 0, 6, 12, 24, 36, and $48 \mathrm{~h}$ post transfection; (B) Induced overexpression of Cx43 and (C) a silencing of Cx43. All experiments conducted with a sample size of $n=3$. ${ }^{*} p$-value $<0.05$ compared to respective transfection control.

Modulation of $\mathrm{Cx} 43$ protein expression through transfection experiments induced alterations in ZO-1 expression. Immunoprecipitation of $\mathrm{Cx} 43$ led to the quantification of bound ZO-1. Cx43 overexpression led to a significant increase in ZO-1 binding at all experimental time points (Figure 6B). Cells transfected with Cx43 siRNA had little to no effect on ZO-1 expression and binding, only at $12 \mathrm{~h}$ post transfection was ZO-1 binding significantly altered Figure 6C). The observed increase in bound ZO-1 to $\mathrm{Cx} 43$ in the overexpressing-Cx43 cells suggests an increase in the recruitment of signaling molecules to the gap junction. 


\subsection{GJIC-Independent: MAPK Signaling}

To determine if Cx43 plays a role in GJIC-independent apoptotic signaling, alterations in the expression of multiple players in the MAPK pathway were identified (Figure 7A). When Cx43 is overexpressed through cDNA, cRaf expression was also significantly upregulated, while silencing $\mathrm{C} \times 43$ induced a significant reduction in cRaf expression (Figure 7B). This suggests that $\mathrm{C} \times 43$ modulates cRaf expression.

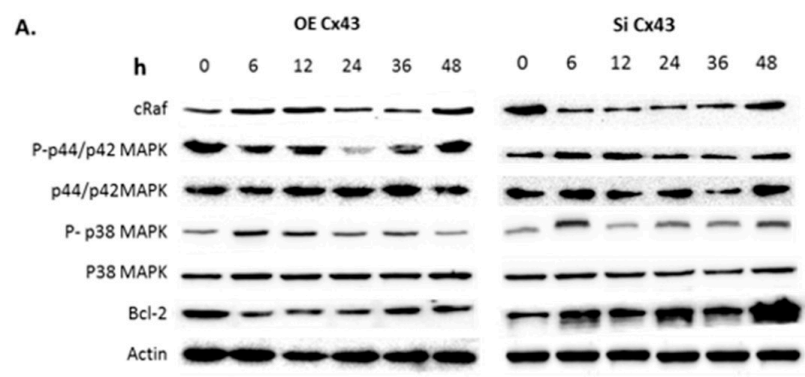

OE CX43

B.

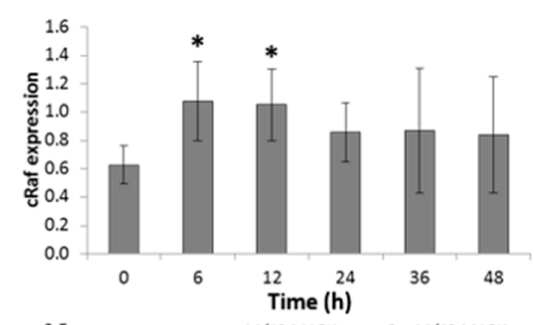

c.

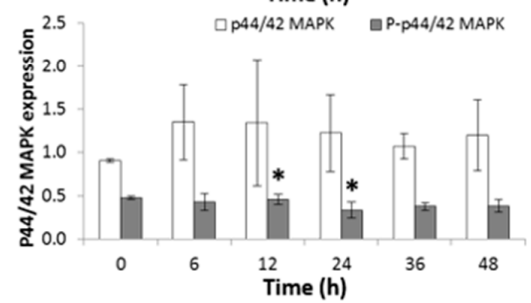

D.

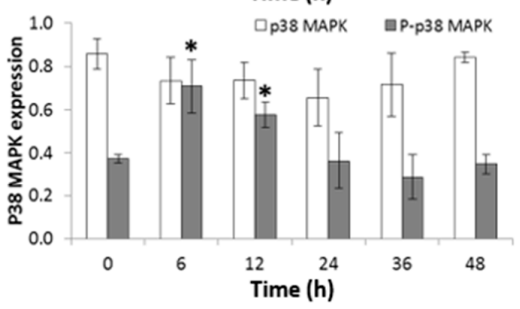

E.

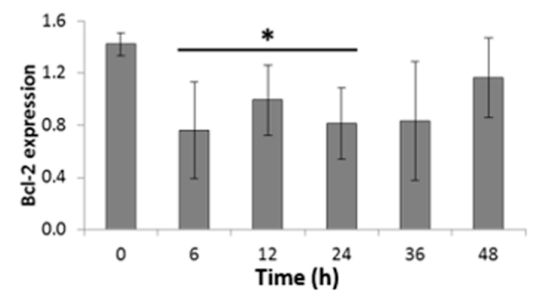

$\operatorname{SiC} \times 43$
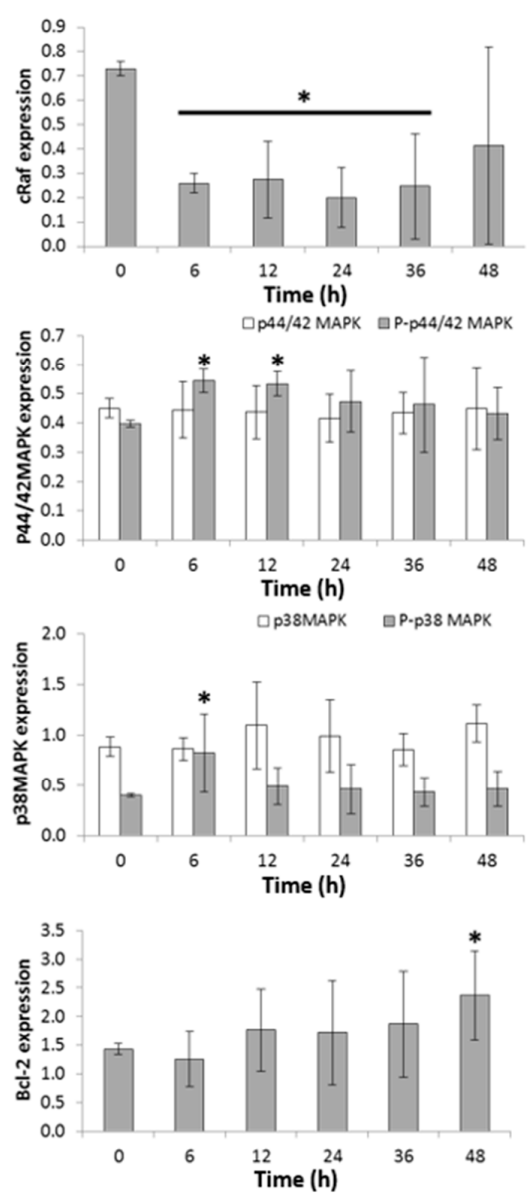

Figure 7. Altering connexin 43 affects expression of signaling molecules involved in cellular survival. (A) Raw and (B-E) graphical representation of western blot analysis of cRaf, phosphorylated (P) and unphosphorylated MAPK (p44/42 and p38), and Bcl-2 expression levels relative to loading control in FMC2 $u$ cells transfected with either cDNA of $\mathrm{Cx} 43$ to induce overexpression (Left) or siRNA to silence $\mathrm{Cx} 43$ (right). Actin used as a loading control. $n=3$. ${ }^{*} p$-value $<0.05$ compared to respective transfection control. 
Overexpression of Cx43 significantly reduced the level of phosphorylated p44/42-MAPK at 24 and $36 \mathrm{~h}$ post transfection ( $p$-value $=0.04324$ and 0.01349 , respectively; Figure 7C). With silencing of Cx43 via siRNA there was a significant increase in the phosphorylation of p44/42-MAPK at 6 and $12 \mathrm{~h}$ post transfection ( $p$-value $=0.00219$ and 0.00355 , respectively; Figure $7 C$ ). There were no changes in p44/42-MAPK expression. This data indicates Cx43 indirectly alters the ERK1/2 signaling cascade, suggesting a role for $\mathrm{C} 43$ in the regulation of proliferation through ERK1/2 signaling.

Due to overexpression of $\mathrm{C} x 43$ there was a corresponding increase in phosphorylated p38-MAPK expression at 6 and $12 \mathrm{~h}$ post transfection ( $p$-value $=0.00649$ and 0.00301 , respectively; Figure 7D). Silencing of Cx43 via siRNA led to a reduction in the phosphorylation of p38-MAPK at $6 \mathrm{~h}$ post transfection $(p$-value $=0.04942$; Figure 7D). There were no changes in p38-MAPK expression due Cx43 silencing. This data indicates $\mathrm{Cx} 43$ indirectly alters the p38-MAPK signaling cascade, suggesting a MAPK-dependent pathway of apoptosis.

Overexpression of Cx43 significantly reduced Bcl-2 expression at 6, 12, and $24 \mathrm{~h}$ post transfection ( $p$-value $<0.05$; Figure 7E). Additionally, the silencing Cx43 induced a significant increase in Bcl-2 expression at $48 \mathrm{~h}$ post transfection ( $p$-value $=0.03119$; Figure $7 \mathrm{E}$ ). This indicates that altering Cx43 expression affects apoptotic signaling through Bcl-2 expression, most likely due to increased phosphorylation of p38-MAPK.

\section{Discussion}

In this study, the female mammary carcinoma cell line FMC2u, derived from a MMTV-PyVT transgenic mouse, was established and characterized over multiple passages. FMC $2 u$ cells are adherent cells of epithelial origin that proliferate rapidly. Growth characteristics and protein analysis suggests that these cells represent an advanced stage of mammary carcinoma in a mouse model. FMC2u cells have been shown to both migrate across an adherent surface and transverse a membrane with 8 micron pores, indicating a more invasive neoplastic cell line. FMC $2 u$ cells are highly proliferative with a doubling time of $24 \mathrm{~h}$. This is a rapidly growing cell line with greater proliferative ability than MCF-7, T47D, MDA-MB-453, and MDA-MB-231 breast cancer cell lines, which double at 29, 36, 47, and $38 \mathrm{~h}$ respectively. The more proliferative the cell line, the more rapidly the tumor grows, and a tendency to have a poorer prognosis.

Hormone receptor profiles are useful diagnostic tools and predictors of therapeutic response. FMC2 $u$ were determined to express low levels of ER and PR, with high expression of HER2. These cells can be considered HER2 + high/ER + low/PR + low. ER is expressed in approximately $80 \%$ of all breast cancers [28], while overexpression of HER2 or both are present in about $15 \%$ of breast cancers [29]. HER2 overexpression is associated with partial resistance to endocrine treatment [30,31], suggesting that this cell line would be unresponsive to endocrine therapy. Additionally, RAS signaling pathways are commonly activated in tumors in which growth-factor-receptor tyrosine kinases, such as HER2, have been overexpressed. Aberrant overexpression or mutational activation of receptor tyrosine kinases can cause hyperactivation of Ras leading to upregulated MAPK signaling [32-34]. The overexpression of HER2 may enhance the MAPK signaling cascade, making this cell line appropriate for MAPK specific research.

Impaired gap junctional intercellular communication (GJIC) has been reported in vivo in many human tumors [35,36] and in vitro in response to oncogenes [37] or tumor promoters [38]. Primary tumors that are initially GJIC impaired become GJIC competent during the metastatic stage [4]. Increased expression of connexins and GJIC correlate with invasiveness and metastasis in a variety of cancer cell types, including breast cancer. Connexin expression profiles change from a metastatic cell to that more similar to a normal breast epithelial cell with expression of metastasis-suppressor gene BRMS1 [39]. This suggests that the connexin composition of gap junctions contributes to the lesions metastatic potential. FMC2u cells were shown to be GJIC competent with strong expression of Cx43. Previous data presented suggests that $\mathrm{C} \times 43$ and $\mathrm{C} \times 46$ are upregulated during late tumor development and metastasis in the parental transgenic mouse model [20]. The report also demonstrated that 
expression of HER2 at the three stages of tumor development is higher in the Early and Late stages than the Pre stage. Furthermore, examination of connexins in 96 breast cancer patients showed that pre-chemotherapy Cx43 expression correlated positively with hormone receptor status both before and after chemotherapy and had a negative correlation with HER2 expression pre-chemotherapy [40]. These findings suggest that there is a negative correlation between Cx43 and HER2 expression.

$\mathrm{PQ} 1$ was shown to have an $\mathrm{IC}_{50}$ of $6.5 \mu \mathrm{M}$ over a $24 \mathrm{~h}$ treatment period. This concentration is 6.5 times that needed to inhibit T47D growth [9], indicating the FMC2u are more resistant to treatment than other cells lines tested. PQ1 is considered a gap junction enhancer due to the observed increase in GJIC and upregulation of connexin expression $[9,20,21]$. Here, PQ1 treatment of FMC2u cells resulted in the upregulation of $\mathrm{Cx} 43$, with a decrease in cellular viability and proliferation rate. This may be explained by the overexpression of $\mathrm{C} \times 43$ induced by PQ1. The role of $\mathrm{C} \times 43$ both as a gap junctional component and independent of GJIC was examined in FMC2u cells with the goal of providing insight into the mechanism behind the anticancer effects of PQ1.

Overexpression by transfection of several connexins, such as Cx43 in tumor and transformed cells, has been shown to inhibit tumorigenicity, leading to the notion that connexins behave like tumor suppressor genes and may be involved in physiological and/or tumor cell growth [41,42] given the critical role of $\mathrm{Cx} 43$ expression. Transfection experiments conducted indicate that a reduction in connexin expression slows neoplastic cell proliferation, while an increase in connexin expression reduces viability. This suggests that there are multiple pathways affected by alterations in Cx43 expression.

Connexins can interact with a large number of scaffolding and signaling proteins that are involved in the regulation of GJIC [43,44]. ZO-1 is a major connexin interacting protein needed for stability of Cx43 at the plasma membrane and endocytosis of the gap junction [45-47]. Disruption of ZO-1-Cx43 interaction in osteosarcoma cells has been shown to lead to a decreased in GJIC and delocalized Cx43, while overexpression of ZO-1 increases GJIC and membranous Cx43 [48]. The dissociation of ZO-1 from Cx43 results in gap junction endocytosis, indicating that $\mathrm{Cx} 43$ internalization is a $\mathrm{ZO}-1$ dependent process [49]. Here, we show that $\mathrm{ZO}-1$ is bound to $\mathrm{Cx} 43$, indicating functional gap junction plaques in FMC2u cells. The observed increase in ZO- 1 with $\mathrm{Cx} 43$ overexpression suggests an increase in recruitment of signaling molecules towards the gap junction and thus an increase in GJIC. This indicates that the upregulation of connexin expression by PQ1 treatment leads to an increase in ZO-1 binding and GJIC. PQ1 has a GJIC-dependent mechanism of action.

Connexins have been shown to be tumor suppressors, but rather than being dependent on cell coupling activity, this effect has also been linked to connexin species-specificity $[41,50]$. Connexin-transfected cells with inhibition of cellular growth and tumor suppression lack gap junction assembly on the cell membrane [51] and have cytoplasmic and nuclear localized connexin expression [41,52], indicating gap junctions and hemichannels are not involved. Additionally, only the c-terminal domain of specifically $\mathrm{C} \times 43$ has been shown to be vital for growth suppression $[53,54]$. These data suggest that expression of connexins, rather than GJIC, corresponds to the regulation of neoplastic growth and suppression. Further study will be explored into the GJIC-independent role of $\mathrm{Cx} 43$ in relation to PQ1 cytotoxicity in FMC2u cells.

The mitogen-activated protein kinase (MAPK) signaling pathways are crucial for the maintenance of the cells. There are three subfamilies of MAPKs: extracellular signal-regulated kinases (ERKs, p44/42 MAPK), c-Jun N-terminal kinases (JNKs), and p38-MAPKs. In general, ERKs are important for cellular proliferation and survival, while JNKs and p38-MAPKs respond to stress stimuli to induce apoptosis [55]. First we observed the expression of cRaf, a protooncogene product that is a main component of many signaling pathways involved in normal cellular proliferation and oncogenic transformation [56]. Upon activation, cRaf phosphorylates the mitogen-activated protein kinase kinase (MEK), which then can activate p44/42 MAPK which propagates the signals [56]. PQ1 treatment led to an upregulation of cRaf expression and a corresponding increase in the activation of p44/42 MAPK, indicating an increase in the ERK1/2 signaling cascade. Unexpectedly, the overexpression of Cx43 led 
to a different result, in which there was an upregulation of cRaf, but a reduction in activation of $\mathrm{p} 44 / 42$ MAPK. This suggests that PQ1 has a Cx43-independent effect on the ERK1/2 signaling cascade.

Transfection of Cx43 siRNA induced a reduction in GJIC while leading to a decrease in cRaf expression, but an activation of $\mathrm{p} 44 / 42$ MAPK. This is the opposite of what was seen in overexpression experiments, indicating that Cx43 may play a role in the regulation of ERK1/2 signaling, and thus cellular growth and survival. This also supports the hypothesis that cells must be removed from a state of growth suppression prior to mitogenic cell signaling [57]. The inhibition of GJIC has previously been shown to precede the activation of p44/42 MAPK [58]. This is confirmed by the observation that reduced expression of Cx43 induced a decrease in GJIC with a corresponding activation of ERK signaling. The Raf-MEK-ERK cascade is a core element of a complex signaling network. More research is needed to determine how Cx43 may contribute to the Raf-MEK-ERK pathway in cancer.

Recent reports have shown the PQ1 has anticancer properties as a potent chemopreventive and chemotherapeutic compound that prevents, inhibits, and attenuates tumorigenesis $[20,21,27]$. The results of the present study are in agreement with the previous studies concerning activation of apoptotic signaling with PQ1 treatment. The cytotoxicity of PQ1 may be attributed to the upregulation of $\mathrm{Cx} 43$. PQ1 also led to the phosphorylation of p38-MAPK. This suggests activation of apoptosis, which is confirmed by the cleavage of caspase- 3 and reduced cellular viability. There was a corresponding reduction in Bcl-2, indicating the cell is more susceptible to apoptotic signaling. These results match those from transfection experiments in which Cx43 is overexpressed. Therefore, PQ1 induces apoptosis via modulation of Cx43, resulting in direct effects on tumor cell survival in a p38 MAPK-dependent manner.

The effects of treatment with the gap junction enhancer PQ1 reduced proliferation and viability, while also inducing an upregulation in Cx43 expression in an epithelial based mammary carcinoma cell culture derived from a malignant murine tumor. PQ1 was shown to not only affect GJIC, but also cellular survival via a MAPK-dependent pathway. The activation of p44/42 MAPK by PQ1 was independent of $\mathrm{C} \times 43$ expression, but modulation of $\mathrm{Cx} 43$ was shown to alter ERK signaling. This introduces the hypothesis that $\mathrm{Cx} 43$ may contribute to the regulation of the ERK1/2 signaling cascade. Additionally, Cx43 may be the key element in the mechanism of PQ1 induced apoptosis. The present study provided the first evidence that PQ1 activates p38 MAPK in an aggressive mammary carcinoma cell line.

Further studies will analyze the effect of Cx43 siRNA and overexpression on PQ1-induced molecular effects, GJIC, and apoptosis. Initial finding of mechanistic link demonstrates that $5 \mu \mathrm{M}$ PQ1 can increase Cx43 expression in prior treated cells with Cx43 siRNA (Supplemental Figure S2). Further analysis is needed to fully examine the effect of PQ1-induced apoptosis.

\section{Experimental Section}

\subsection{Ethics Statement}

Husbandry of animals is conducted by the Comparative Medical Group (CMG) at the College of Veterinary Medicine at Kansas State University (Manhattan, KS, USA). The CMG animal facilities are fully accredited by the Association for Assessment and Accreditation of Laboratory Animal Care, International (AAALAC). The compliance to aspects of animal welfare law is regularly monitored by the veterinary staff. Animal care and use protocols were approved by the Institutional Animal Care and Use Committee (IACUC) at Kansas State University, Manhattan following NIH guidelines.

\subsection{Establishment of Cell Cultures}

FMC2 $u$ cultures were derived from malignant tumors from the transgenic strain FVB/N-Tg(MMTV-PyVT)634Mul/J. Female mice were approximately 12 weeks old with no treatment prior to tissue removal. Whole tumors were washed with sterile PBS three times and cut in half prior to trypsinization for $30 \mathrm{~min}$ at $37^{\circ} \mathrm{C}$. After incubation, tumors were removed and trypsin was neutralized 
with RPMI with insulin, followed by centrifugation at $2000 \mathrm{rpm}$ for $5 \mathrm{~min}$. Supernatant was aspirated and cells resuspended in RPMI supplemented with insulin and $10 \%$ fetal bovine serum (FBS) and then plated in a T-75 tissue culture flask. Cells were maintained in RPMI medium supplemented with 10\% FBS (Atlanta Biologicals, Lawrenceville, GA, USA) at $37^{\circ} \mathrm{C}$ with $5 \% \mathrm{CO}_{2}$ in T-125 flasks.

\subsection{Media Test}

Cells were seeded in 6-well plates in RPMI with insulin, RPMI, DMEM, DMEM/F12, MEM, or L15. All media contained 10\% FBS. Images were taken of the monolayer growth every $24 \mathrm{~h}$. Once cells were $100 \%$ confluent, cell count and viability were determined by AO/PI (see below).

\subsection{Cell Doubling Time}

Cell doubling times at $36{ }^{\circ} \mathrm{C}$ were measured by counting the number of viable cells from trypsinized monolayers by Trypan blue exclusion. Counts were performed at 12 to $24 \mathrm{~h}$ intervals.

\subsection{Colony Formation}

100,000 cells were seeded between $0.8 \%$ agarose RPMI 10\% FBS and $0.4 \%$ agarose RPMI $10 \%$ FBS. Images were taken every $24 \mathrm{~h}$ to determine if individual cells could form a colony in a 3 dimensional medium.

\subsection{Migration Assay}

Cells were grown to $90 \%$ confluency. Two cuts crossing each other in the center of the well were made to create a "wound" on the cell monolayer. Cells were washed with $1 \mathrm{~mL}$ of media and then incubated in RPMI $10 \% \mathrm{FBS}$ at $37^{\circ} \mathrm{C}$. Images were taken every $12 \mathrm{~h}$ until the wound was closed and cells were confluent.

\subsection{Invasion Assay}

Cells were seeded into the upper chamber of a transwell with RPMI $0 \%$ FBS. The lower chamber contained RMPI 10\% FBS. Cells were incubated for varying time points $(24,48,72 \mathrm{~h})$ and the number of cells in the lower chamber were counted by Trypan blue.

\subsection{Cell Recovery}

Cells were frozen down using $500 \mu \mathrm{L}$ of cell culture freezing medium from Invitrogen (Cat. \# 12648-010; Life Technologies, Grand Island, NY, USA) and allowed to sit at $-20^{\circ} \mathrm{C}$ for $1 \mathrm{~h}$ prior to exposure to $-80^{\circ} \mathrm{C}$. Cryovials were removed from $-80^{\circ} \mathrm{C}$ storage and rapidly thawed with warm media. Cells were gently agitated. Samples were transferred to $15 \mathrm{~mL}$ conical tubes and $5 \mathrm{~mL}$ of warm media was added. Cells were allowed to incubate for $10 \mathrm{~min}$ at $37^{\circ} \mathrm{C}$, followed by centrifugation (5 min at $2000 \mathrm{rpm}$ ). Supernatant was aspirated out and cells resuspended in PBS and Trypan Blue for viability testing.

\subsection{Antibodies}

Antibodies against cleaved caspase 3, Cx43, Cx46, ER ( $\alpha$ and $\beta$ ), PR, and Bcl-2 (Santa Cruz Biotechnologies, Santa Cruz, CA, USA), phospho-p42/44 MAP kinase, cRaf, and HER2 (Cell Signaling, Boston, MA, USA), and actin (Sigma-Aldrich, St. Louis, MO, USA) were used.

\subsection{Western Blot Assay}

Whole cell extractions conducted using lysis buffer (20 mM Tris pH 7.5, $0.5 \mathrm{mM}$ EDTA, $0.5 \mathrm{mM}$ EGTA, and 0.5\% Triton X-100) with 1:1000 dilution of protease inhibitors (Sigma-Aldrich, Saint Louis, MO, USA). Tissue was sonicated, followed by centrifugation at $13,000 \mathrm{rpm}$ for $30 \mathrm{~min}$ at $4{ }^{\circ} \mathrm{C}$. Twenty-five $\mu \mathrm{g}$ of whole-cell extract was resolved by $10 \%$ SDS polyacrylamide gel electrophoresis 
(PAGE) and transferred to nitrocellulose membrane (Midwest Scientific, Saint Louis, MO, USA). Nitrocellulose membrane was blocked in $5 \%$ milk for an hour at room temperature and then incubated with monoclonal antibodies at a dilution of 1:1000. Western blots were detected by enhanced chemiluminescence detection reagents (Pierce, Rockford, IL, USA) and visualized by Fluorochem E imaging system (ProteinSimple, San Jose, CA, USA).

\subsection{Immunoprecipitation Assay}

For immunoprecipitation $1 \mathrm{mg}$ of total protein was precleared with $10 \mu \mathrm{L}$ of $\operatorname{IgG}$ and $10 \mu \mathrm{L}$ protein A/G agarose beads (sc-2003, Santa Cruz Biotechnologies, Santa Cruz, CA, USA). Samples were incubated at $4{ }^{\circ} \mathrm{C}$ for $30 \mathrm{~min}$, followed by centrifugation at $1500 \mathrm{rpm}$ for $5 \mathrm{~min}$ to pellet the $\mathrm{IgG}$ agarose conjugate. Five microliters of primary antibody were added to each sample and incubated at $4{ }^{\circ} \mathrm{C}$ overnight. This was followed by addition of $20 \mu \mathrm{L}$ protein A/G agarose beads and $2 \mathrm{~h}$ incubation. Sample was centrifuged at $1500 \mathrm{rpm}$ for $5 \mathrm{~min}$ to pellet the primary antibody agarose conjugate. Supernatant was removed and remaining pellet used for Western blot analysis.

\subsection{Treatment with Gap Junction Enhancers}

Compound PQ1, 6-methoxy-8-[(3-aminopropyl)amino]-4-methyl-5-(3-trifluoromethyl-phenyloxy) quinolines, was prepared by following the reported procedure [18]. Cells were seeded into 6-well plates in RPMI 10\% FBS and allowed to attach overnight. Cells dosed with varying concentrations of each compound in RPMI 0\% FBS for 24, 48, or $72 \mathrm{~h}$.

\subsection{Overexpression and Silencing of Connexins}

cDNA from human Cx43 was purchased from Addgene (Cambridge, MA, USA; plasmid \#40907). Connexin 43 siRNA (sc-35091) was purchased from Santa Cruz Biotechnolgoy (Santa Cruz, CA, USA). Connexin 46 siRNA (S100131670) was purchased from Qiagen (Germantown, MD, USA). DNA and siRNAs were transfected according to the manufacturer's specifications using Polyplus (Illkirch, France) jetPEI-FluoR (106-05N) and Mirus (Madison, WI, USA) TransIT-siQUEST (MIR 2114) transfection reagent, respectively. Briefly, cells were cultured in six-well plates and incubated under their normal growth conditions. When cells reached 50\% confluency, $5 \mu \mathrm{g}$ of DNA or $3.2 \mu \mathrm{g}$ of siRNA complex was mixed with transfection reagent and incubated at room temperature for $15 \mathrm{~min}$ prior to applying to the cells. Cells were either utilized for in vitro experimentation or the cell lysates were collected and prepared for Western blot analysis.

\subsection{Proliferation and Viability}

Post treatment period, the media was removed and saved. The cells were trypsinized for $5 \mathrm{~min}$ at $37^{\circ} \mathrm{C}$. Cells were scraped off the plate and transferred to the saved media. Wells were washed with $3 \mathrm{~mL}$ of PBS and elution was saved. Media, cells, wash were centrifuged for $4 \mathrm{~min}$ at $2000 \mathrm{rpm}$. Supernatant was aspirated and cells resuspended in PBS. A cell sample was mixed with Acridine Orange/Propidium Iodide (AO/PI) at a 1:1 ratio. Cell count and viability was determined by Nexcelom (Lawrence, MA, USA) cell counter.

\subsection{Scrape Load Dye Transfer}

Cells were grown to $90 \%$ confluency on coverslips in 6-well plates. Cells were washed three times with PBS. The $2.5 \mu \mathrm{L}$ mixture of $1 \%(w / v)$ Lucifer yellow and $0.75 \%(w / v)$ of Rhodamine-dextran was added in the center of the coverslip. Two cuts crossing each other in the center of the coverslip were made. After $3 \mathrm{~min}$, cells were washed three times with PBS and incubated at $37^{\circ} \mathrm{C}$ in tissue culture media for $20 \mathrm{~min}$. The cells were then washed with PBS and fixed in $2.5 \%$ paraformaldehyde for $10 \mathrm{~min}$. Cells were mounted on a slide, sealed and visualized under a fluorescence microscope at $10 \times$ objective. Three independent experiments with sample size of 3 per each treatment were performed. 


\subsection{Statistical Analysis}

Significance was considered at a $p$-value $\leqslant 0.05$ using Student's $t$-test analysis. All data are presented as mean $\pm 95 \%$ confidence interval of at least three independent experiments.

\section{Conclusions}

A novel cell line, FMC2u, from the primary tumor with an aggressive, metastatic phenotype was used to evaluate the role of Cx43 in PQ1-induced cytotoxicity. The findings show that PQ1 decreased cell viability and proliferation and induced upregulation of $\mathrm{Cx} 43$. Furthermore, PQ1 exerts GJIC-independent effects by modulating ERK1/2 and p38-MAPK signaling and by decreasing the expression of Bcl-2 and increasing the cleavage of pro-caspase-3. However, overexpression of Cx43 resulted in reduced expression of p44/MAPK, while PQ1 treatment had the opposite effect, which suggests that PQ1 affects the Raf-MEK-ERK cascade independent of Cx43 upregulation. Therefore, the mechanism behind PQ1-induced cytotoxicity in FMC2u is likely due to the change in Cx43 expression. PQ1-induced apoptosis through the upregulation of Cx43 may depend on p38 MAPK, highlighting that the effect of PQ1 on gap junctions as well as cellular survival via a MAPK-dependent pathway.

Supplementary Materials: The following are available online at http://www.mdpi.com/1422-0067/17/2/178/s1.

Acknowledgments: The project described was supported by grant number R15CA152922 from the National Institutes of Health (NIH).

Author Contributions: Study conception and design: Stephanie N. Shishido, Thu A. Nguyen; Acquisition of data: Stephanie N. Shishido; Analysis and interpretation of data: Stephanie N. Shishido, Thu A. Nguyen; Drafting of manuscript: Stephanie N. Shishido, Thu A. Nguyen; Critical revision: Stephanie N. Shishido, Thu A. Nguyen.

Conflicts of Interest: The authors declare no conflict of interest.

\section{References}

1. Siegel, R.; Ward, E.; Brawley, O.; Jemal, A. Cancer statistics, 2011: The impact of eliminating socioeconomic and racial disparities on premature cancer deaths. CA Cancer J. Clin. 2011, 61, 212-236. [CrossRef] [PubMed]

2. Shishido, S.N.; Delahaye, A.; Beck, A.; Nguyen, T.A. The MMTV-PyVT transgenic mouse as a multistage model for mammary carcinoma and the efficacy of antineoplastic treatment. J. Cancer Ther. 2013, 4, 1187-1197. [CrossRef]

3. Willecke, K.; Eiberger, J.; Degen, J.; Eckardt, D.; Romualdi, A.; Guldenagel, M.; Deutsch, U.; Sohl, G. Structural and functional diversity of connexin genes in the mouse and human genome. Biol. Chem. 2002, 383, 725-737. [CrossRef] [PubMed]

4. Mesnil, M.; Crespin, S.; Avanzo, J.L.; Zaidan-Dagli, M.L. Defective gap junctional intercellular communication in the carcinogenic process. Biochim. Biophys. Acta 2005, 1719, 125-145. [CrossRef] [PubMed]

5. Pointis, G.; Fiorini, C.; Gilleron, J.; Carette, D.; Segretain, D. Connexins as precocious markers and molecular targets for chemical and pharmacological agents in carcinogenesis. Curr. Med. Chem. 2007, 14, 2288-2303. [CrossRef] [PubMed]

6. Naus, C.C.; Laird, D.W. Implications and challenges of connexin connections to cancer. Nat. Rev. 2010, 10, 435-441. [CrossRef] [PubMed]

7. Jiang, J.X.; Gu, S. Gap junction- and hemichannel-independent actions of connexins. Biochim. Biophys. Acta 2005, 1711, 208-214. [CrossRef] [PubMed]

8. Gakhar, G.; Hua, D.H.; Nguyen, T.A. Combinational treatment of gap junctional activator and tamoxifen in breast cancer cells. Anticancer Drugs 2010, 21, 77-88. [CrossRef] [PubMed]

9. Gakhar, G.; Ohira, T.; Shi, A.B.; Hua, D.H.; Nguyen, T.A. Antitumor effect of substituted quinolines in breast cancer cells. Drug Dev. Res. 2008, 69, 526-534. [CrossRef]

10. Bernzweig, J.; Heiniger, B.; Prasain, K.; Lu, J.; Hua, D.H.; Nguyen, T.A. Anti-breast cancer agents, quinolines, targeting gap junction. Med. Chem. 2011, 7, 448-453. [CrossRef] [PubMed] 
11. Koo, H.M.; VanBrocklin, M.; McWilliams, M.J.; Leppla, S.H.; Duesbery, N.S.; Vande Woude, G.F. Apoptosis and melanogenesis in human melanoma cells induced by anthrax lethal factor inactivation of mitogen-activated protein kinase kinase. Proc. Natl. Acad. Sci. USA 2002, 99, 3052-3057. [CrossRef] [PubMed]

12. Johnson, G.L.; Lapadat, R. Mitogen-activated protein kinase pathways mediated by ERK, JNK, and p38 protein kinases. Science 2002, 298, 1911-1912. [CrossRef] [PubMed]

13. Nagata, Y.; Todokoro, K. Requirement of activation of JNK and p38 for environmental stress-induced erythroid differentiation and apoptosis and of inhibition of ERK for apoptosis. Blood 1999, 94, 853-863. [PubMed]

14. Cory, S.; Huang, D.C.; Adams, J.M. The Bcl-2 family: Roles in cell survival and oncogenesis. Oncogene 2003, 22, 8590-8607. [CrossRef] [PubMed]

15. Lipponen, P.; Pietilainen, T.; Kosma, V.M.; Aaltomaa, S.; Eskelinen, M.; Syrjanen, K. Apoptosis suppressing protein Bcl-2 is expressed in well-differentiated breast carcinomas with favourable prognosis. J. Pathol. 1995, 177, 49-55. [CrossRef] [PubMed]

16. Silvestrini, R.; Veneroni, S.; Daidone, M.G.; Benini, E.; Boracchi, P.; Mezzetti, M.; di Fronzo, G.; Rilke, F.; Veronesi, $\mathrm{U}$. The $\mathrm{Bcl}-2$ protein: A prognostic indicator strongly related to $\mathrm{p} 53$ protein in lymph node-negative breast cancer patients. J. Natl. Cancer Inst. 1994, 86, 499-504. [CrossRef] [PubMed]

17. Paik, S.; Shak, S.; Tang, G.; Kim, C.; Baker, J.; Cronin, M.; Baehner, F.L.; Walker, M.G.; Watson, D.; Park, T.; et al. A multigene assay to predict recurrence of tamoxifen-treated, node-negative breast cancer. N. Engl. J. Med. 2004, 351, 2817-2826. [CrossRef] [PubMed]

18. Shi, A.; Nguyen, T.A.; Battina, S.K.; Rana, S.; Takemoto, D.J.; Chiang, P.K.; Hua, D.H. Synthesis and anti-breast cancer activities of substituted quinolines. Bioorg. Med. Chem. Lett. 2008, 18, 3364-3368. [CrossRef] [PubMed]

19. Heiniger, B.; Gakhar, G.; Prasain, K.; Hua, D.H.; Nguyen, T.A. Second-generation substituted quinolines as anticancer drugs for breast cancer. Anticancer Res. 2010, 30, 3927-3932. [PubMed]

20. Shishido, S.N.; Delahaye, A.; Beck, A.; Nguyen, T.A. The anticancer effect of PQ1 in the MMTV-PyVT mouse model. Int. J. Cancer 2014, 134, 1474-1483. [CrossRef] [PubMed]

21. Shishido, S.N.; Nguyen, T.A. Gap junction enhancer increases efficacy of cisplatin to attenuate mammary tumor growth. PLoS ONE 2012, 7, e44963. [CrossRef] [PubMed]

22. Giepmans, B.N.; Moolenaar, W.H. The gap junction protein connexin43 interacts with the second PDZ domain of the zona occludens-1 protein. Curr. Biol. 1998, 8, 931-934. [CrossRef]

23. Shaul, Y.D.; Seger, R. The MEK/ERK cascade: From signaling specificity to diverse functions. Biochim. Biophys. Acta 2007, 1773, 1213-1226. [CrossRef] [PubMed]

24. Wan, P.T.; Garnett, M.J.; Roe, S.M.; Lee, S.; Niculescu-Duvaz, D.; Good, V.M.; Jones, C.M.; Marshall, C.J.; Springer, C.J.; Barford, D.; et al. Mechanism of activation of the RAF-ERK signaling pathway by oncogenic mutations of B-RAF. Cell 2004, 116, 855-867. [CrossRef]

25. Iervolino, A.; Trisciuoglio, D.; Ribatti, D.; Candiloro, A.; Biroccio, A.; Zupi, G.; del Bufalo, D. Bcl-2 overexpression in human melanoma cells increases angiogenesis through VEGF mRNA stabilization and HIF-1-mediated transcriptional activity. FASEB J. 2002, 16, 1453-1455. [CrossRef] [PubMed]

26. De Chiara, G.; Marcocci, M.E.; Torcia, M.; Lucibello, M.; Rosini, P.; Bonini, P.; Higashimoto, Y.; Damonte, G.; Armirotti, A.; Amodei, S.; et al. Bcl-2 phosphorylation by p38 MAPK-Identification of target sites and biologic consequences. J. Biol. Chem. 2006, 281, 21353-21361. [CrossRef] [PubMed]

27. Ding, Y.; Nguyen, T.A. PQ1, a quinoline derivative, induces apoptosis in T47D breast cancer cells through activation of caspase-8 and caspase-9. Apoptosis 2013, 18, 1071-1082. [CrossRef] [PubMed]

28. Harvey, J.M.; Clark, G.M.; Osborne, C.K.; Allred, D.C. Estrogen receptor status by immunohistochemistry is superior to the ligand-binding assay for predicting response to adjuvant endocrine therapy in breast cancer. J. Clin. Oncol. 1999, 17, 1474-1481. [PubMed]

29. Slamon, D.J.; Clark, G.M.; Wong, S.G.; Levin, W.J.; Ullrich, A.; McGuire, W.L. Human breast cancer: Correlation of relapse and survival with amplification of the HER-2/neu oncogene. Science 1987, 235, 177-182. [CrossRef] [PubMed]

30. Borg, A.; Baldetorp, B.; Ferno, M.; Killander, D.; Olsson, H.; Ryden, S.; Sigurdsson, H. ERBB2 amplification is associated with tamoxifen resistance in steroid-receptor positive breast-cancer. Cancer Lett. 1994, 81, 137-144. [CrossRef] 
31. Wright, C.; Nicholson, S.; Angus, B.; Sainsbury, J.R.C.; Farndon, J.; Cairns, J.; Harris, A.L.; Horne, C.H.W. Relationship between c-erbB-2 protein product expression and response to endocrine therapy in advanced breast-cancer. Br. J. Cancer 1992, 65, 118-121. [CrossRef] [PubMed]

32. Lynch, T.J.; Bell, D.W.; Sordella, R.; Gurubhagavatula, S.; Okimoto, R.A.; Brannigan, B.W.; Harris, P.L.; Haserlat, S.M.; Supko, J.G.; Haluska, F.G.; et al. Activating mutations in the epidermal growth factor receptor underlying responsiveness of non-small-cell lung cancer to gefitinib. N. Engl. J. Med. 2004, 350, 2129-2139. [CrossRef] [PubMed]

33. Stephens, P.; Hunter, C.; Bignell, G.; Edkins, S.; Davies, H.; Teague, J.; Stevens, C.; O'Meara, S.; Smith, R.; Parker, A.; et al. Lung cancer: Intragenic ERBB2 kinase mutations in tumours. Nature 2004, 431, 525-526. [CrossRef] [PubMed]

34. Hynes, N.E.; Lane, H.A. Erbb receptors and cancer: The complexity of targeted inhibitors. Nat. Rev. Cancer 2005, 5, 341-354. [CrossRef] [PubMed]

35. Krutovskikh, V.; Mazzoleni, G.; Mironov, N.; Omori, Y.; Aguelon, A.M.; Mesnil, M.; Berger, F.; Partensky, C.; Yamasaki, H. Altered homologous and heterologous gap-junctional intercellular communication in primary human liver tumors associated with aberrant protein localization but not gene mutation of connexin 32 . 1994, 56, 87-94. [CrossRef] [PubMed]

36. Hirschi, K.K.; Xu, C.E.; Tsukamoto, T.; Sager, R. Gap junction genes Cx26 and Cx43 individually suppress the cancer phenotype of human mammary carcinoma cells and restore differentiation potential. Cell Growth Differ. 1996, 7, 861-870. [PubMed]

37. Jou, Y.S.; Layhe, B.; Matesic, D.F.; Chang, C.C.; de Feijter, A.W.; Lockwood, L.; Welsch, C.W.; Klaunig, J.E.; Trosko, J.E. Inhibition of gap junctional intercellular communication and malignant transformation of rat liver epithelial cells by neu oncogene. Carcinogenesis 1995, 16, 311-317. [CrossRef] [PubMed]

38. Budunova, I.V.; Carbajal, S.; Slaga, T.J. Effect of diverse tumor promoters on the expression of gap-junctional proteins connexin (Cx)26, Cx31.1, and Cx43 in SENCAR mouse epidermis. Mol. Carcinog. 1996, 15, $202-214$. [CrossRef]

39. Saunders, M.M.; Seraj, M.J.; Li, Z.; Zhou, Z.; Winter, C.R.; Welch, D.R.; Donahue, H.J. Breast cancer metastatic potential correlates with a breakdown in homospecific and heterospecific gap junctional intercellular communication. Cancer Res. 2001, 61, 1765-1767. [PubMed]

40. Teleki, I.; Krenacs, T.; Szasz, M.A.; Kulka, J.; Wichmann, B.; Leo, C.; Papassotiropoulos, B.; Riemenschnitter, C.; Moch, H.; Varga, Z. The potential prognostic value of connexin 26 and 46 expression in neoadjuvant-treated breast cancer. BMC Cancer 2013, 13, 50. [CrossRef] [PubMed]

41. Huang, R.P.; Fan, Y.; Hossain, M.Z.; Peng, A.; Zeng, Z.L.; Boynton, A.L. Reversion of the neoplastic phenotype of human glioblastoma cells by connexin 43 (Cx43). Cancer Res. 1998, 58, 5089-5096. [PubMed]

42. Princen, F.; Robe, P.; Gros, D.; Jarry-Guichard, T.; Gielen, J.; Merville, M.P.; Bours, V. Rat gap junction connexin-30 inhibits proliferation of glioma cell lines. Carcinogenesis 2001, 22, 507-513. [CrossRef] [PubMed]

43. Herve, J.C.; Bourmeyster, N.; Sarrouilhe, D.; Duffy, H.S. Gap junctional complexes: From partners to functions. Prog. Biophys. Mol. Biol. 2007, 94, 29-65. [CrossRef] [PubMed]

44. Wei, C.J.; Xu, X.; Lo, C.W. Connexins and cell signaling in development and disease. Annu. Rev. Cell Dev. Biol. 2004, 20, 811-838. [CrossRef] [PubMed]

45. Barker, R.J.; Price, R.L.; Gourdie, R.G. Increased association of ZO-1 with connexin43 during remodeling of cardiac gap junctions. Circ. Res. 2002, 90, 317-324. [CrossRef] [PubMed]

46. Duffy, H.S.; Ashton, A.W.; O’Donnell, P.; Coombs, W.; Taffet, S.M.; Delmar, M.; Spray, D.C. Regulation of connexin43 protein complexes by intracellular acidification. Circ. Res. 2004, 94, 215-222. [CrossRef] [PubMed]

47. Segretain, D.; Fiorini, C.; Decrouy, X.; Defamie, N.; Prat, J.R.; Pointis, G. A proposed role for ZO-1 in targeting connexin 43 gap junctions to the endocytic pathway. Biochimie 2004, 86, 241-244. [CrossRef] [PubMed]

48. Laing, J.G.; Chou, B.C.; Steinberg, T.H. ZO-1 alters the plasma membrane localization and function of Cx43 in osteoblastic cells. J. Cell Sci. 2005, 118, 2167-2176. [CrossRef] [PubMed]

49. Gilleron, J.; Fiorini, C.; Carette, D.; Avondet, C.; Falk, M.M.; Segretain, D.; Pointis, G. Molecular reorganization of $\mathrm{Cx} 43, \mathrm{ZO}-1$ and src complexes during the endocytosis of gap junction plaques in response to a non-genomic carcinogen. J. Cell Sci. 2008, 121, 4069-4078. [CrossRef] [PubMed] 
50. Bond, S.L.; Bechberger, J.F.; Khoo, N.K.; Naus, C.C. Transfection of c6 glioma cells with connexin32: The effects of expression of a nonendogenous gap junction protein. Cell Growth Differ. Mol. Biol. J. Am. Assoc. Cancer Res. 1994, 5, 179-186.

51. Musil, L.S.; Cunningham, B.A.; Edelman, G.M.; Goodenough, D.A. Differential phosphorylation of the gap junction protein connexin43 in junctional communication-competent and -deficient cell lines. J. Cell Biol. 1990, 111, 2077-2088. [CrossRef] [PubMed]

52. Qin, H.; Shao, Q.; Curtis, H.; Galipeau, J.; Belliveau, D.J.; Wang, T.; Alaoui-Jamali, M.A.; Laird, D.W. Retroviral delivery of connexin genes to human breast tumor cells inhibits in vivo tumor growth by a mechanism that is independent of significant gap junctional intercellular communication. J. Biol. Chem. 2002, 277, 29132-29138. [CrossRef] [PubMed]

53. Dang, X.T.; Doble, B.W.; Kardami, E. The carboxy-tail of connexin-43 localizes to the nucleus and inhibits cell growth. Mol. Cell. Biochem. 2003, 242, 35-38. [CrossRef] [PubMed]

54. Moorby, C.; Patel, M. Dual functions for connexins: Cx43 regulates growth independently of gap junction formation. Exp. Cell Res. 2001, 271, 238-248. [CrossRef] [PubMed]

55. Wada, T.; Penninger, J.M. Mitogen-activated protein kinases in apoptosis regulation. Oncogene 2004, 23, 2838-2849. [CrossRef] [PubMed]

56. Chen, J.; Fujii, K.; Zhang, L.; Roberts, T.; Fu, H. Raf-1 promotes cell survival by antagonizing apoptosis signal-regulating kinase 1 through a MEK-ERK independent mechanism. Proc. Natl. Acad. Sci. USA 2001, 98, 7783-7788. [CrossRef] [PubMed]

57. Trosko, J.E.; Chang, C.C.; Medcalf, A. Mechanisms of tumor promotion: Potential role of intercellular communication. Cancer Invest. 1983, 1, 511-526. [CrossRef] [PubMed]

58. Rummel, A.M.; Trosko, J.E.; Wilson, M.R.; Upham, B.L. Polycyclic aromatic hydrocarbons with bay-like regions inhibited gap junctional intercellular communication and stimulated MAPK activity. Toxicol. Sci. 1999, 49, 232-240. [CrossRef] [PubMed]

(C) 2016 by the authors; licensee MDPI, Basel, Switzerland. This article is an open access article distributed under the terms and conditions of the Creative Commons by Attribution (CC-BY) license (http:/ / creativecommons.org/licenses/by/4.0/). 